\title{
PREDICATORS OF SATISFACTION AND DISSATISFACTION OF MEDICAL WORKERS WITH THEIR WORK IN MEDICAL INSTITUTION
}

\author{
Tetyana Vezhnovets' \\ Department of Healthcare Management \\ Bohomolets National Medical University \\ 13 Shevchenko blvd., Kyiv, Ukraine, 01601 \\ managementnmu@gmail.com \\ Valentyn Pariy \\ Department of Healthcare Management \\ Bohomolets National Medical University \\ 13 Shevchenko blvd., Kyiv, Ukraine, 01601 \\ managementnmu@gmail.com \\ Ivan Vyshnyvetskyy \\ Department of Healthcare Management \\ Bohomolets National Medical University \\ 13 Shevchenko blvd., Kyiv, Ukraine, 01601 \\ iv.nov.med@gmail.com \\ Maksym Moskalenko \\ Department of Healthcare Management \\ Bohomolets National Medical University \\ 13 Shevchenko blvd., Kyiv, Ukraine, 01601 \\ maksmoko@gmail.com
}

\footnotetext{
Abstract

The resulting criterion of assessment of staff management effectiveness in health protection institution is a satisfaction of medical workers with their work. So, it is important to know the predictors of satisfaction and dissatisfaction with the work.

The aim of the research was in determination of the predictors of satisfaction and dissatisfaction with the work in medical institution.

There was carried out the interrogation of 395 doctors (52\%) and hospital nurses (48\%) of the institutions of Kyiv city (Ukraine) by the form (response $81 \%$ ), formed of 12 questions and 3 answers "Yes", "No", "Not decided) ( $\alpha$ of Cronbach 0,82). Pearson's consent coefficient $\left(\chi^{2}\right)$ was used for determination of the differences in the answer structures.

The reliable difference in the index of general satisfaction of doctors (95\% DI: 69,87\%; 76,31\%) and hospital nurses (95\% DI: 70,10\%; 75,39\%) was not revealed. Analogously there were not revealed such differences in the index of general dissatisfaction of doctors (95\% DI: 17,97 \%; 24,09\%) and hospital nurses (95 \% DI: 16,76 \%, 21,80\%). The structures of answers to the question about patients' attitude did not reliably $(\mathrm{p}<0,05)$ differ $(94,12 \%$ of doctors, $79,52 \%$ of hospital nurses answered "YES"), about improvement of medical help at material stimulation by patients ( $20 \%$ of doctors, $13,25 \%$ of hospital nurses - "YES"), about the choice of own profession again (41,18 \% of doctors, $20,48 \%$ hospital nurses - "NO").

It was determined that the predicators of medical workers' satisfaction with their work are an attitude of colleges, patients, leader, climate in collective, and the ones of dissatisfaction - a salary, management system, labor conditions.
}

Keywords: satisfaction with work, doctors, hospital nurses.

\section{Introduction}

The resulting criterion of assessment of staff management effectiveness in health protection institution is medical workers' satisfaction of with their work [1]. Satisfaction of medical workers is connected with the quality of primary medical help [2]. Their dissatisfaction is considered as a risk factor of burnout syndrome development and the one of care for patients [2] Medical workers' 
satisfaction influences patients' one that is the one of criteria of assessment of medical care quality in an institution [3]. Tarja Kvist et al established that hospital nurses' satisfaction conditions the high quality of medical help [4], and dissatisfaction - low-quality medical help, bad clinical results and higher staff turnover [5]. The most important prognostic factor of medical workers' satisfaction is patients'perception of the care quality [6]

The efforts of staff management in health care institution must be directed on creation of conditions that help staff to get satisfaction from the work. For this aim it is necessary to be able to assess and to analyze the predictors of satisfaction and dissatisfaction of medical workers with their work in an institution.

According to the literary data, the different indices of medical workers' satisfaction with their work are registered in the world. Thus in China 53,7 \% of medical workers are satisfied with their work [7]. But only $3 \%$ of doctors in hospitals and $27 \%$ of doctors of primary medical care in China are satisfied with salary [8]. In Tanzania 73,9\% of medical workers are satisfied with their work but only $11,6 \%$ among them are satisfied with their salary [9]. In Poland $71,32 \%$ of anesthesiologists are satisfied with their work [10]. In Germany 52,2\% of surgeons are satisfied with their labor [11]. According to the data of Tyssen R. et al, American doctors are less satisfied with their labor comparing with Canadian and Norwegian ones that is conditioned by the different systems of the medical branch financing [12].

There is a series of interrelated factors that condition medical workers' dissatisfaction with the work: high level of responsibility, unsatisfactory labor conditions, long working shift [13], absence of professional autonomy, total control of leaders, dangerousness of working places, aggression from patients and their relatives [14], low level of recompense, inadequate salary, bad access to professional development or its absence [15]. In Ukraine hospital nurses' dissatisfaction with the work is conditioned by the low level of salary, work content, absence of autonomy and possibility of professional growth [16].

But it is very important to have medical workers, satisfied with their work in institution. Okello DR \& Gilson L think that satisfied and motivated medical workers play the extremely important role in provision of effective and high-quality medical services [17].

According to the literary data, there are five main parameters of the work that form workers' satisfaction: work content (interesting tasks, cognition of new, responsibility), recompense (salary and additional privileges, gotten by a worker), advancement (possibility of career growth), system of management and leadership (leader's ability to give technical and moral support, relations with a leader), climate in collective and colleges (competence degree and social support level) [18].

\section{Aim of research}

Determination of predicators of satisfaction and dissatisfaction of doctors and hospital nurses with their work in medical institution.

\section{Materials and methods}

There was carried out the interrogation of 395 medical workers of institutions of city Kyiv by the form, elaborated at the department of management of health protection at the National medical university, named after O. O. Bogomolets (response $81 \%$ ). The form consisted of 12 questions and 3 possible answers "Yes", "No", "Not decided" to each question. In the form the questions № 1-8 - are the direct ones as to satisfaction and dissatisfaction with the work and № 9-12 - indirect ones (Table 1).

The index of general satisfaction (in \%) was calculated as the mean value of the share of received answers "Yes" to the direct questions № 1-8. The index of general dissatisfaction (in \%) was calculated as the mean value of the share of received answers "No" to the direct questions № 1-8.

The form was filled by respondents anonymously. They noted their age, length of service in institution, sex and post (doctor or hospital nurse). For verifying the validity of gotten results, there was carried out the interrogation of professors of the department of health protection management of the national medical university, named after O. O. Bogomolets before the research. The form reliability was verified by Alf Cronbach's index $(\alpha=0,82)$. 
Table 1

Questions of the form of the study of satisfaction with the work

\begin{tabular}{ll}
\hline № & Question \\
\hline 1 & I am satisfied with the work content in institution \\
3 & I am satisfied with the salary in institution \\
4 & I am satisfied with the management system in institution \\
5 & I am satisfied with the labor conditions in institution \\
6 & I am satisfied with the collective of institution \\
7 & I am satisfied with the colleges' attitude to me \\
8 & I am satisfied with the leader's attitude to me \\
9 & I am satisfied with patients' attitude to me \\
10 & I would work better, if my salary was higher \\
11 & If I was materially stimulated by patients, I would give better medical help \\
12 & I would choice my profession again, if it would be necessary to choose the new one \\
\end{tabular}

The results of research were analyzed using IBM SPSS Statistics Base v.22 after purification of the data and coding of the results of anonymous respondents. Pearson's consent coefficient $\left(\chi^{2}\right)$ was used for determination of the differences in the answer structures.

The mean age of respondents was 43,3 $\pm 0,3$ years, mean length of service- $19,01 \pm 0,5$ years. Among respondents there were $75,6 \%$ of women $-24,4 \%$ of men. Among interrogated persons there were $52 \%$ of doctors and $48 \%$ of hospital nurses.

\section{Results}

The results of interrogation of medical workers as to their general satisfaction or dissatisfaction with the work are presented in the Tables 2,3 .

\section{Table 2}

Mean value of the index of general satisfaction with work in the group of hospital nurses and in the one of doctors

\begin{tabular}{cccc}
\hline post & Mean value (\%) & DI & DI \\
& & $\mathbf{- 9 5} \%$ & $\mathbf{9 5}$ \\
\hline Hospital nurses & 72,74 & 70,10 & 75,39 \\
Doctors & 73,09 & 69,87 & 76,31
\end{tabular}

Table 3

Mean value of the index of general dissatisfaction with work in the group of hospital nurses and in the one of doctors

\begin{tabular}{|c|c|c|c|}
\hline post & Mean value (\%) & $\begin{array}{c}\text { DI } \\
-95 \%\end{array}$ & $\begin{array}{c}\text { DI } \\
+95\end{array}$ \\
\hline Hospital nurses & 19,28 & 16,76 & 21,80 \\
\hline Doctors & 21,03 & 17,97 & 24,09 \\
\hline
\end{tabular}


The presented data testify to the absences of the differences of indices of medical workers' general satisfaction and general dissatisfaction with their work in the group of hospital nurses and in the one of doctors.

The analysis of the structures of answers to the questions from the form in both groups is presented in the Table 4.

Table 4

Distribution of answers to the questions from the form of determination of doctors' and hospital nurses' satisfaction with their work (in \%)

\begin{tabular}{|c|c|c|c|c|c|c|c|c|}
\hline \multirow{2}{*}{$\begin{array}{c}\text { № } \\
\text { question }\end{array}$} & \multicolumn{3}{|c|}{ Distribution of hospital nurses' answers } & \multicolumn{3}{|c|}{ Distribution of doctors' answers } & \multirow{2}{*}{$\chi^{2}$} & \multirow{2}{*}{$\mathbf{P}$} \\
\hline & yes & no & not decided & yes & no & not decided & & \\
\hline 1 & 2 & 3 & 4 & 5 & 6 & 7 & 8 & 9 \\
\hline 1 & 84,34 & 8,43 & 7,23 & 74,12 & 15,29 & 10,59 & 2,74 & $>0,05$ \\
\hline 2 & 30,12 & 66,27 & 3,61 & 16,47 & 81,18 & 2,35 & 4,86 & $>0,05$ \\
\hline 3 & 56,63 & 22,89 & 20,48 & 62,35 & 21,18 & 16,47 & 0,65 & $>0,05$ \\
\hline 4 & 50,6 & 39,76 & 9,64 & 48,24 & 41,18 & 10,58 & 0,1 & $>0,05$ \\
\hline 5 & 95,18 & 1,2 & 3,62 & 97,64 & 1,18 & 1,18 & 1,08 & $>0,05$ \\
\hline 6 & 96,39 & 1,2 & 2,41 & 98,82 & 1,18 & 0 & 2,07 & $>0,05$ \\
\hline 7 & 89,16 & 7,23 & 3,61 & 92,94 & 3,53 & 3,53 & 1,13 & $>0,05$ \\
\hline 8 & 79,52 & 7,23 & 13,25 & 94,12 & 3,53 & 2,35 & 8,55 & $<0,05$ \\
\hline 9 & 53,01 & 32,53 & 14,46 & 57,64 & 34,12 & 8,24 & 1,6 & $>0,05$ \\
\hline 10 & 13,25 & 69,88 & 16,87 & 20 & 75,29 & 4,71 & 7,11 & $<0,05$ \\
\hline 11 & 69,88 & 20,48 & 9,64 & 51,76 & 41,18 & 7,06 & 8,14 & $<0,05$ \\
\hline 12 & 30,12 & 53,01 & 16,87 & 22,35 & 64,71 & 12,94 & 2,4 & $>0,05$ \\
\hline
\end{tabular}

The structures of answers of hospital nurses and doctors to the questions from the form almost did not differ $(\mathrm{p}>0,05)$. But according to Pearson's consent criterion $\chi^{2}$ there were established the reliable differences in the structures of answers to the following questions "I am satisfied with patients' attitude to me" (No. 8), "If I was materially stimulated by patients, I would give better medical help" (No. 10), "I would choice my profession again, if it would be necessary to choose the new one" (No. 11) $(\mathrm{p}<0,05)$.

In the structure of doctors' answers there was the higher share of persons, satisfied with patients' attitude to them, than in the structure of hospital nurses' answers (94,12\% against 79,52\%). At the same time in the structure of hospital nurses' answers the more share was dissatisfied with patients' attitude and answered "No" to this question (7,23\% against 3,53\%). At the same time in the structure of hospital nurses' answers to the question No. 8 the more share of persons could not decide about satisfaction with patients' attitude to them than in the structure of doctors $(13,25 \%$ against 8,55\%).

In the structure of doctors' answers to the question No. 10 "If I was materially stimulated by patients, I would give better medical help" the more share of persons answered "Yes" than in the structure of hospital nurses' answers (20\% against 13,25\%). But in the structure of answers the essential share of both doctors $(75,29 \%)$, and hospital nurses $(69,88 \%)$ answered "No" to this question. It is necessary to note, that in the structure of hospital nurses' answers to this question the essential share of persons could not choose the answer (16,87\% of hospital nurses against $4,71 \%$ of doctors). 
The structure of answers to the question No. 9 "I would work better, if my salary was higher" did not reliably differ in both groups $(p>0,05)$. Most hospital nurses and doctors answered "Yes" to this question (53,01\% against 57,64\%).

In the structure of doctors' answers there was revealed the more share of persons, who answered "No" to the question No. 11 "I would choice my profession again, if it would be necessary to choose the new one", than in the one of hospital nurses' structure (41,18\% against 20,48\%). At the same time in the structure of hospital nurses' answers to this question the more share answered "Yes" (69,88\% against 51,76\%).

At the same time it must be noted, that in the structures of hospital nurses' and doctors' answers the least shares of answer "Yes" were to the question No. 2 "I am satisfied with the salary", No. 3 "I am satisfied with the management system in institution" and No. 4 "I am satisfied with labor conditions". At the same time the most shares of answers were to the question № 5 "I am satisfied with the collective of institution" and No. 6 "I am satisfied with colleges' attitude to me".

\section{Discussion of results}

The received results testify that hospital nurses and doctors have no differences in the indices of general satisfaction and dissatisfaction with their work.

The most shares of answers "Yes" that reach almost $100 \%$ are noted in the structures of answers to the questions "I am satisfied with the collective of institution" and "I am satisfied with colleges' attitude to me". So, medical workers get satisfaction from the climate in collective, from the work in united collective. The aforesaid is proved by the literary data as to the positive influence of colleges' support and set team work, built on trusting principles on the satisfaction [19, 20].

In the structure of answers there were determined the lowest shares of positive answers in both doctors and hospital nurses to the questions "I am satisfied with the salary" (16,47\% and $30,12 \%$ respectively), "I am satisfied with the labor conditions" (48,24 \% against 50,6 \%) and "I am satisfied with the management system in institution" (62,35\% against $56,36 \%)$. It is also proved by the literature data. According to the data of Wu D et al the most important factors of the negative influence of doctors' satisfaction are the low incomes and duration of working day. Only 30,0\% of Chinese doctors were satisfied with their salary and 50,0\% of doctors - with duration of their working day [8]. This idea is also shared by Atif $\mathrm{K}$ et al that also established the negative influence of salary on the satisfaction with work [21].

In Ukraine in 2016 the mean salary varied within 160-250 \$, and the mean salary of medical workers varied within 130-180 \$. So, such low salary negatively influences the satisfaction of medical workers with their work.

It was established, that the structures of answers to the question "I am satisfied with patients' attitude" reliably differed in doctors and hospital nurses. The more share of positive answers was in the structure of doctors' answers. It is probably conditioned by the fact that hospital nurses have more contact with patients, the emotional burnout syndrome develops more often and earlier in them that negatively influences the attitudes with patients [22].

At the same time the structures of answers to the questions "If I was materially stimulated by patients, I would give better medical help" (No. 10) and "I would choice my profession again, if it would be necessary to choose the new one" (No. 11) are reliably different $(p<0,05)$.

It must be noted, that most doctors and hospital nurses answered "No" to the question "If I was materially stimulated by patients, I would give better medical help". But in doctors' structure there was a bit more share of persons, who answered "Yes", comparing with hospital nurses.

Probably, the lower status in hierarchy, patients' attitude, lower salary in medical institution conditioned the fact that the more share of hospital nurses answered "Yes" to the question as to the possibility to choose the new non-medical profession. But $41,18 \%$ of doctors answered "No" to this question against $20,48 \%$ of hospital nurses. The aforesaid testifies to the doctors' dissatisfaction with their profession, to their disillusion. The analogous dissatisfaction was determined also among Chinese doctors [8]. According to the data of Wu D. et al., in China only 4,5\% want their children to become doctors [8]. It is conditioned by the low salary (34\%), high risk for life (17\%), patients' aggression (9\%). 
The analysis testifies that the predicators of medical workers' satisfaction are colleges', patients', leader's attitude, climate in collective and the ones of dissatisfaction - salary, management system, labor conditions. Determination of aforesaid predicators gives a possibility to analyze the effectiveness of staff management in health protection institution and elaborate the arrangements for the influence on the predicators of dissatisfaction with the work to improve the staff satisfaction that is a guarantee of medical care for patients.

\section{Conclusions}

1. The reliable difference in the index of doctors' and hospital nurses' general satisfaction and dissatisfaction was not revealed.

2. The structures of doctors' and hospital nurses' answers reliably differed to the question about satisfaction with patients' attitude $(94,12 \%$ of doctors answered "Yes", 79,52 \% of hospital nurses), about the improvement of medical help at patients' material stimulation (20\% of doctors - "YES", 13,25\% of hospital nurses), about the choice of own profession again (41,18 \% of doctors - "NO", 20,48 \% of hospital nurses).

3. It was determined, that the predicators of medical workers' satisfaction are colleges', patients', leader's attitude, climate in collective and the ones of dissatisfaction - salary, management system, labor conditions.

\section{Recommendations}

The introduction of periodical study of medical workers' satisfaction with their work by leaders of health protection institutions allows determine the predictors of dissatisfaction and timely elaborate the arrangements for minimization of their negative influence on medical help quality.

\section{References}

[1] Chang, C.-S., Chang, H.-H. (2007). Effects of Internal Marketing on Nurse Job Satisfaction and Organizational Commitment: Example of Medical Centers in Southern Taiwan. Journal of Nursing Research, 15 (4), 265-274. doi: 10.1097/01.jnr.0000387623.02931.a3

[2] Sanchez-Piedra, C. A., Jaruseviciene, L., Prado-Galbarro, F. J., Liseckiene, I., Sanchez-Alonso, F., Garcia-Perez, S., Sarria Santamera, A. (2017). Factors associated with professional satisfaction in primary care: Results from EUprimecare project. European Journal of General Practice, 23 (1), 114-120. doi: 10.1080/13814788.2017.1305350

[3] Goetz, K., Marx, M., Marx, I., Brodowski, M., Nafula, M., Prytherch, H. et. al. (2015). Working Atmosphere and Job Satisfaction of Health Care Staff in Kenya: An Exploratory Study. BioMed Research International, 2015, 1-7. doi: 10.1155/2015/256205

[4] Kvist, T., Voutilainen, A., Mäntynen, R., Vehviläinen-Julkunen, K. (2014). The relationship between patients' perceptions of care quality and three factors: nursing staff job satisfaction, organizational characteristics and patient age. BMC Health Services Research, 14 (1), 466. doi: 10.1186/1472-6963-14-466

[5] Goetz, K., Campbell, S. M., Steinhaeuser, J., Broge, B., Willms, S., Szecsenyi, J. (2011). Evaluation of job satisfaction of practice staff and general practitioners: an exploratory study. BMC Family Practice, 12 (1), 137. doi: 10.1186/1471-2296-12-137

[6] Chang, W.-Y., Ma, J.-C., Chiu, H.-T., Lin, K.-C., Lee, P.-H. (2009). Job satisfaction and perceptions of quality of patient care, collaboration and teamwork in acute care hospitals. Journal of Advanced Nursing, 65 (9), 1946-1955. doi: 10.1111/j.1365-2648.2009.05085.x

[7] Lu, H., Barriball, K. L., Zhang, X., While, A. E. (2012). Job satisfaction among hospital nurses revisited: A systematic review. International Journal of Nursing Studies, 49 (8), 1017-1038. doi: 10.1016/ j.ijnurstu.2011.11.009

[8] Wu, D., Wang, Y., Lam, K. F., Hesketh, T. (2014). Health system reforms, violence against doctors and job satisfaction in the medical profession: a cross-sectional survey in Zhejiang Province, Eastern China. BMJ Open, 4 (12), e006431. doi: 10.1136/bmjopen-2014-006431

[9] Mbaruku, G. M., Larson, E., Kimweri, A., Kruk, M. E. (2014). What elements of the work environment are most responsible for health worker dissatisfaction in rural primary care clinics in Tanzania? Human Resources for Health, 12 (1). doi: 10.1186/1478-4491-12-38 
[10] Gaszynska, E., Stankiewicz-Rudnicki, M., Szatko, F., Wieczorek, A., Gaszynski, T. (2014). Life Satisfaction and Work-Related Satisfaction among Anesthesiologists in Poland. The Scientific World Journal, 2014, 1-9. doi: 10.1155/2014/601865

[11] Bauer, J., Groneberg, D. A. (2015). Working conditions of physicians in hospitals - A comparison of specialties in German hospitals (iCept-Study). DMW - Deutsche Medizinische Wochenschrift, 140 (15), e150-e158. doi: 10.1055/s-0041-103165

[12] Tyssen, R., Palmer, K. S., Solberg, I. B., Voltmer, E., Frank, E. (2013). Physicians' perceptions of quality of care, professional autonomy, and job satisfaction in Canada, Norway, and the United States. BMC Health Services Research, 13 (1), 516. doi: 10.1186/1472-6963-13-516

[13] Kingma, M. (2003). Economic incentive in community nursing: attraction, rejection or indifference? Human Resources for Health, 1 (1). doi: 10.1186/1478-4491-1-2

[14] Huang, W. X., Wang, J. Y., Zhang, L. W. (2011). Studying the grass-roots core doctors' satisfaction on their job in underdeveloped area of Guangdong. Chin Health Serv Manag, 4, 304-306.

[15] Yami, A., Hamza, L., Hassen, A., Jira, C., Sudhakar, M. (2011). Job Satisfaction and Its Determinants Among Health Workers in Jimma University Specialized Hospital, Southwest Ethiopia Ethiopian. Journal of Health Sciences, 21, 19-27.

[16] Zyukov, O. L., Mishurenko, O. V. (2010). Analysis of satisfaction of nurses profession in medical institutions of different profiles. Ukraine. Health of the nation, 4 (16), 104-110.

[17] Okello, D. R. O., Gilson, L. (2015). Exploring the influence of trust relationships on motivation in the health sector: a systematic review. Human Resources for Health, 13 (1), 16. doi: 10.1186/s12960-015-0007-5

[18] Hulin, C. L., Judge, T. A.; Borman, W. C., Ligen, D. R., Klimoski, R. J. (Eds.) (2003). Handbook of psychology: Industrial and organizational psychology. Hoboken: Wiley, 255-276.

[19] Henry, L. S., Henry, J. D. (2007). Using a Strengths-Based Approach to Build Caring Work Environments. Workplace Health \& Safety, 55 (12), 501-503. doi: 10.1177/216507990705501204

[20] Duffield, C. M., Roche, M. A., Blay, N., Stasa, H. (2010). Nursing unit managers, staff retention and the work environment. Journal of Clinical Nursing, 20 (1-2), 23-33. doi: 10.1111/j.1365-2702.2010.03478.x

[21] Atif, K., Khan, H. U., Maqbool, S. (2015). Job satisfaction among doctors, a multi-faceted subject studied at a tertiary care hospital in Lahore. Pakistan Journal of Medical Sciences, 31 (3), 610-614. doi: $10.12669 /$ pjms.313.7402

[22] Vezhnovets, T. A., Pariy, V. D. (2016). Burnout syndrome among the medical personnel of surgical departments from the perspective of personnel management. Ukraine. Health of the nation, 1-2, 41-47. 